\author{
臨 床 \\ 他覚的聴力検查としての MASTER ${ }^{\circledR}$ の有用性についての検討 \\ 武田真紀子 ・畠史子・長谷川賢作 \\ 硲田 猛真* ・ 北野 博也

\section{Evaluation of the Audiometric Usefulness of the Auditory Steady-state Response Using the Multiple Auditory Steady-state Response}

\author{
Makiko Takeda, Fumiko Hata, Kensaku Hasegawa and Hiroya Kitano \\ (Tottori University) \\ Takema Sakoda \\ (Wakayama Nisseki Medical Center)
}

\begin{abstract}
Objective: To evaluate the audiometric usefulness of the auditory steady-state response (ASSR) using the multiple auditory steady-state response (MASTER $\left.{ }^{\circledR}\right)$.

Design: (1)In normal adults (aged 25-45 years old), comparisons of the behavioral thresholds for pure tones and the ASSR thresholds were compared. (2)In supposedly normal infants (aged 3-45 months old), the click ABR thresholds and ASSR thresholds were compared. (3)In patients (aged 6-81 years old), the behavioral thresholds for pure tones, the ASSR thresholds, and click ABR thresholds were compared.

Results: (1)In normal adults, the behavioral thresholds for pure tones of $0.5,1,2$, and $4 \mathrm{kHz}$ were 9. $7 \pm 4,7.8 \pm 3.5,8.9 \pm 5$, and $6.1 \pm 6.3 \mathrm{~dB}$, respectively. In addition, the ASSR thresholds for carrier frequencies of $0.5,1,2$, and $4 \mathrm{kHz}$ were $40.6 \pm 9.4,33.9 \pm 7,29.4 \pm 5.4$, and $32.8 \pm 4.6 \mathrm{~dB}$, respectively. (2) In the infants, the click ABR thresholds were $20 \pm 7.3 \mathrm{~dB}$, while the ASSR thresholds for carrier frequencies of $0.5,1,2$, and $4 \mathrm{kHz}$ were $55 \pm 9.3,44.4 \pm 13.9,34.8 \pm 11.6$, and $40.7 \pm 14.4 \mathrm{~dB}$, respectively. (3In the patients, correlation coefficients of behavioral thresholds and ASSR thresholds were 0.65 at $0.5 \mathrm{kHz}, 0.85$ at $1 \mathrm{kHz}, 0.82$ at $2 \mathrm{kHz}$, and 0.77 at $4 \mathrm{kHz}$. The correlation coefficients of behavioral thresholds and click ABR thresholds were 0.80 at $0.5 \mathrm{kHz}, 0.86$ at $1 \mathrm{kHz}, 0.90$ at $2 \mathrm{kHz}$, and 0.83 at 4 $\mathrm{kHz}$.

Conclusion: On average, the thresholds for the ASSR were higher than the behavioral thresholds, and the discrepancies were larger at low frequencies. For a better physiologic audiometry estimation of the lower frequencies, the optimal modulation frequency should be investigated.
\end{abstract}

Key words : auditory steady-state response (ASSR), ABR, pure tone audiometry

はじめに

正弦波的振幅変調音 (sinusoidally amplitude modulated tone: SAM 音) を用いて得られる $\mathrm{ASSR}^{11}$ は, ABR よりも
周波数特異性が高く低音域までの他覚的閾值が得られる 検查として近年注目されている. Bio-Logic 社から市販さ れた MASTER ${ }^{\circledR}$ (multiple auditory steady-state response) 
は，合成 SAM 音を用いることで左右両耳の 4 周波数の 聴力を同時に判定できるため, 検查時間が短縮され臨床 応用が可能になったとされる2).われわれの施設で行っ た症例をもとに, 標準純音聴力検查 (以下, 純音), ASSR, $\mathrm{ABR}$ の各䦭值の統計学的解析を行い, その有用性々問題 点について検討した.

\section{対 象}

まず聴力正常者での検討を目的とし，難聴を有しない 成人 $25 \sim 45$ 歳（中央值：27 歳）の 11 名（男女比 $=8$ : 3） 22 耳を対象として純音と ASSR の各周波数の閾值を 比較した。また，乳幼児例は ABR の閾值が $30 \mathrm{dBnHL}$ 以 下で, ほぼ正常聴力と推定される生後 3 力月〜 3 歳（中 央值：5力月）の乳幼児 16 名（男女比 $=8: 8 ）$ を対象之 し，ABR とASSR の闇值を比較した。乳幼児に関しては トリクロリールシロップ®またはエスクレ坐薬 ${ }^{\circledR}$ を使用 し，睡眠下で検查を行った，乳幼児例は，新生児聴覚ス クリーニング後の精查として検査を行ったものが半数で あった（表 1)。次に，2004 年 4 月から 2005 年 6 月に鳥 取大学医学部耳鼻咽喉科において聴力の精查を行った 6 $\sim 81$ 歳（中央值： 52 歳）の 65 名（男女比 $=31: 34 ） を$ 対象として, 純音と ASSR およびABR の閾值の相関を調 べた。対象症例の疾患の内訳は突発性難聴をはじめとし

表 1 乳幼児例の内訳（生後 3 力月～ 3 歳）

\begin{tabular}{ll}
\hline \hline 新生児聴覚スクリーニング後 & 8 \\
乳幼児健診後 & 6 \\
言語発達遅滞 & 2 \\
\hline
\end{tabular}

計 16 例

表 2 対象例の疾患の内訳（6〜81 歳 $)$

\begin{tabular}{|c|c|c|c|}
\hline 突発性難聴 & 19 & 慢性中耳炎 & 10 \\
\hline 音響外傷 & 1 & 真珠腫性中耳炎 & 5 \\
\hline 低音障害型感音難聴 & 1 & 癒着性中耳炎 & 1 \\
\hline 一側壟 & 5 & 耳小骨奇形 & 1 \\
\hline 前庭水管拡大症 & 1 & 鼓膜炎 & 1 \\
\hline 遺伝性進行性難聴 & 1 & & \\
\hline 錐体尖囊腫 & 2 & 原因不明感音難聴 & 9 \\
\hline 脳腫瘍 & 4 & 原因不明混合難聴 & 2 \\
\hline 大動脈炎症候群 & 1 & & \\
\hline めまい & 1 & & \\
\hline
\end{tabular}

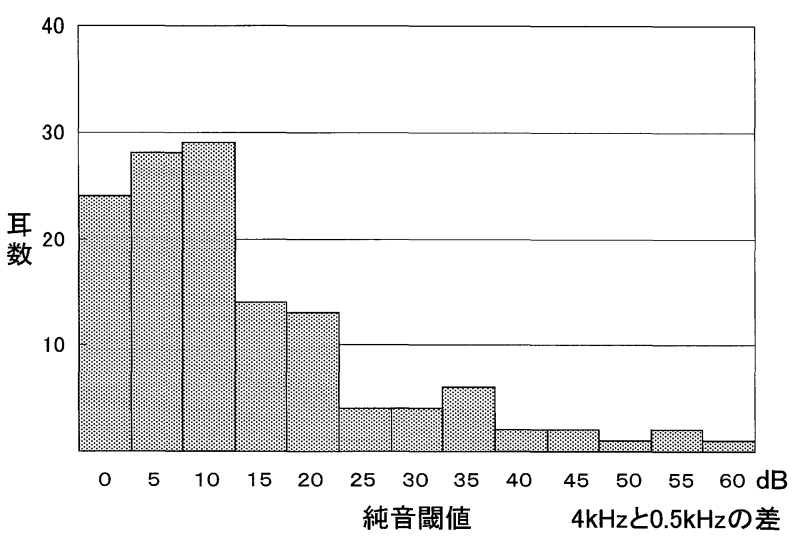

図 1 対象症例の聴力像

た感音難聴が 37 例（57\%）であった（表 2)。また， $0.5 \mathrm{KHz}$ と $4 \mathrm{KHz}$ の閾值の差が $20 \mathrm{~dB}$ 以内の症例が 108 耳（83\%）であり，水平型あるいは漸傾型の聴力像がほ とんどであった（図1).

\section{方法}

1. ASSR

Bio-Logic 社の MASTER ${ }^{\circledR}$ を用い, 音源はインサートイ ヤホンより提示した。搬送周波数 $0.5,1,2,4 \mathrm{kHz}$ に 対し, 変調周波数は MASTER ${ }^{\circledR}$ のデフォールトのまま右 91，94，96，99 Hz，左 $82 ， 84 ， 87 ， 89 \mathrm{~Hz}$ の条件を用 い，刺激音の変調は $\mathrm{AM}^{2}$ 変調を使用した． 4 周波数の左 右同時測定で, $80 \mathrm{dBHL}$ 以上は 1 周波数ずつの測定を行っ た。関電極を頭頂部，基準電極を後頸部，接地電極を前 額部において記録した。

\section{2. $A B R$}

Bio-Logic社のauditory evoked response Ver. 2 を使用し, 音源はASSR と同じインサートイヤホンから click 音を提 示し, 関電極を頭頂部, 基準電極を耳後部, 接地電極を 前額部において記録した。

純音，ABR，ASSR のいずれもスケールアウトのデー 夕は除いて統計学的解析を行った。

\section{結 果}

1. 成人聴力正常例の純音と ASSR の閾值

純音閾值に対する ASSR の閾值は， $0.5 \mathrm{kHz}$ において 平均 $9.7 \mathrm{~dB}$ に対し平均 $40.6 \mathrm{dBnHL}, 1 \mathrm{kHz}$ において平 均 $7.8 \mathrm{~dB}$ に対し平均 $33.9 \mathrm{dBnHL}, 2 \mathrm{kHz}$ に扮いて平均 $8.9 \mathrm{~dB}$ に対し平均 $29.4 \mathrm{dBnHL}, 4 \mathrm{kHz}$ において平均 $6.1 \mathrm{~dB}$ 
表 3 成人聴力正常者における純音と ASSR の閾値（N=22 耳）

\begin{tabular}{l|c|c|c|c}
\hline \hline & $0.5 \mathrm{kHz}$ & $1 \mathrm{kHz}$ & $2 \mathrm{kHz}$ & $4 \mathrm{kHz}$ \\
\hline 純音 $(\mathrm{dB})$ & $9.7 \pm 4$ & $7.8 \pm 3.5$ & $8.9 \pm 5$ & $6.1 \pm 6.3$ \\
\hline ASSR (dBnHL) & $40.6 \pm 9.4$ & $33.9 \pm 7$ & $29.4 \pm 5.4$ & $32.8 \pm 4.6$
\end{tabular}

表 $4 \mathrm{ABR} 30 \mathrm{dBnHL}$ 以下の乳幼児例における ASSR の閾值

\begin{tabular}{l|c|c|c|c|c}
\hline \multirow{2}{*}{} & \multirow{2}{*}{ ABR } & \multicolumn{4}{|c}{ ASSR } \\
\cline { 2 - 6 } & & $0.5 \mathrm{kHz}$ & $1 \mathrm{kHz}$ & $2 \mathrm{kHz}$ & $4 \mathrm{kHz}$ \\
\hline $\mathrm{N}$ (耳数) & 27 & 20 & 25 & 27 & 27 \\
\hline 平均 $(\mathrm{dBnHL}) \pm 1 \mathrm{SD}$ & $20 \pm 7.3$ & $55 \pm 9.3$ & $44.4 \pm 13.9$ & $34.8 \pm 11.6$ & $40.7 \pm 14.4$
\end{tabular}

表 5 純音と ASSR, ABR の相関解析結果のまとめ

\begin{tabular}{|c|c|c|c|c|c|c|}
\hline & \multicolumn{3}{|c|}{ 純音と ASSR } & \multicolumn{3}{|c|}{ 純音と ABR } \\
\hline & 耳数 & 相関係数 & 自由度調整 $\mathrm{R}^{2}$ 值 & 耳数 & 相関係数 & 自由度調整 $\mathrm{R}^{2}$ 值 \\
\hline $0.5 \mathrm{kHz}$ & 87 & 0.65 & 0.42 & 49 & 0.80 & 0.62 \\
\hline $1 \mathrm{kHz}$ & 101 & 0.85 & 0.71 & 51 & 0.86 & 0.73 \\
\hline $2 \mathrm{kHz}$ & 106 & 0.82 & 0.66 & 50 & 0.90 & 0.81 \\
\hline $4 \mathrm{kHz}$ & 99 & 0.77 & 0.59 & 49 & 0.83 & 0.69 \\
\hline
\end{tabular}

に対し平均 $32.8 \mathrm{dBnHL}$ であり, ASSR の閾值が純音閾值 より約 $20 \mathrm{~dB}$ 高い值を示し,特に $0.5 \mathrm{kHz}$ において ASSR の閾值が純音閾值より約 $30 \mathrm{~dB}$ 高く, ばらつきが多かっ た (表 3).

\section{2. 乳幼児聴力正常例の ABR とASSR の閾值}

$\mathrm{ABR}$ の閾值が平均 $20 \mathrm{dBnHL}$ であるのに対し, ASSR の 各周波数の閾值は $0.5 \mathrm{kHz}$ で平均 $55 \mathrm{dBnHL}, 1 \mathrm{kHz}$ で平 均 $44.4 \mathrm{dBnHL}, 2 \mathrm{kHz}$ で平均 $34.8 \mathrm{dBnHL}, 4 \mathrm{kHz}$ で平 均 $40.7 \mathrm{dBnHL}$ と高く, 特に $0.5 \mathrm{kHz}$ の閾值が高い傾向 がみられた（表 4）. $60 \mathrm{~dB}$ から $10 \mathrm{~dB}$ ステップで音圧を

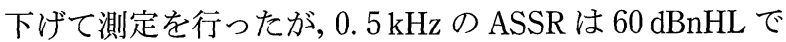
も反応が得られなかったために解析から省いた症例があ り, $1 \sim 4 \mathrm{kHz}$ の他の周波数より反応の検出が覀かった.

3. 純音と ASSR, ABR の閾值の相関（6〜81 歳）

各周波数における純音と ASSR の閾值の間には有意な 相関を認めた $(\mathrm{p}<0.0001)$. 相関係数は $0.5 \mathrm{kHz}$ におい て $0.65,1 \mathrm{kHz}$ において $0.85,2 \mathrm{kHz}$ において 0.82 , $4 \mathrm{kHz}$ において 0.77 であり， $1 \mathrm{kHz}$ および $2 \mathrm{kHz}$ の相関
が最も高くばらつきも少なく, $0.5 \mathrm{kHz}$ の相関が最も低 くばらつきが多かった（図 2)。また，閾值が得られた耳 数が $1 \sim 4 \mathrm{kHz}$ においては 100 耳前後であったのに対し， $0.5 \mathrm{kHz}$ の ASSR は 87 耳と検出が覀かった。同症例のう ち ABR も同時に行った症例を解析したところ, やはり 各周波数において純音と $\mathrm{ABR}$ の閾值の間に有意な相関 を認めた $(\mathrm{p}<0.0001)$. その相関係数は $0.5 \mathrm{kHz}$ におい て $0.80,1 \mathrm{kHz}$ において $0.86,2 \mathrm{kHz}$ において 0.90 , $4 \mathrm{kHz}$ において 0.83 であり, 純音との相関が最も高いの はASSR と同様に $1,2 \mathrm{kHz}$ であった（図 3). 各周波数 における純音との相関は ABR と ASSR は同等であった (表 5).

\section{考察}

他覚的聴力検査としては ABR が汎用されており信頼 度も高いが，ABR の刺激音は click 音を用いるため周波 数特異性が低く，特に低音域の聴力を反映しないとされ る. ABR によって低音域の閾值を得るため tone-pip, tone- 

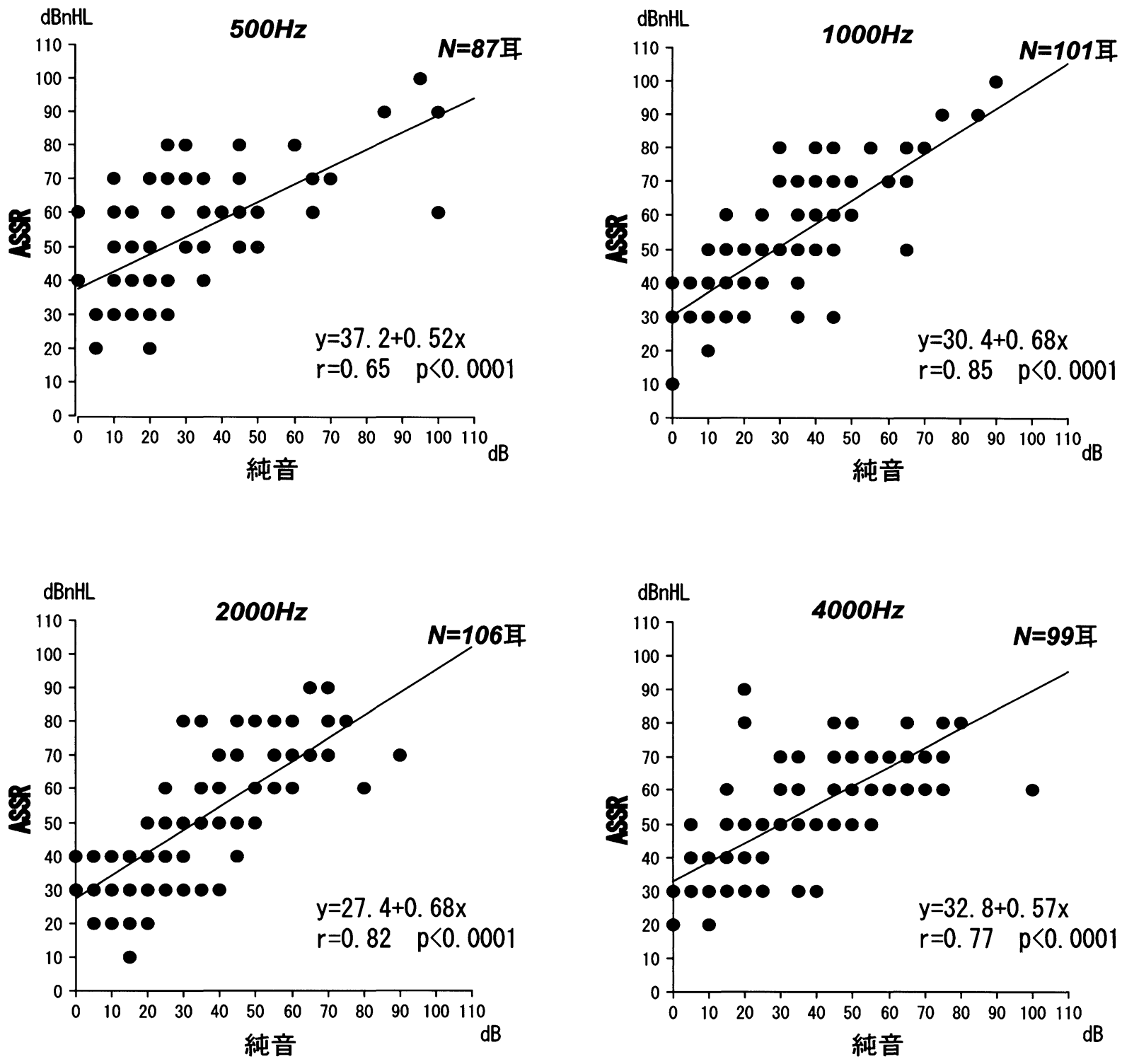

図 2 純音閾値とASSR 閾值の相関

burst などの刺激音が用いられてきたが，反応の検出度， 閾值の信頼性に関してあまり満足のいく結果が得られて いない3). 周波数特異性の高い SAM 音を用いて得られる ASSRは純音との相関が高いとされ，近年他覚的検查とし て注目を集めている ${ }^{4)}$. 9 .

変調周波数に関しては amplitude-modulated（AM）音 に対し, AM 変調と FM 変調を同時に加える mixedmodulated (MM), さらに exponentially-modulated $\left(\mathrm{AM}^{2}\right)$ 音を使用すると反応の検出率が上がるが， $\mathrm{AM}$ 音と比べ 周波数特異性が下がるとされる ${ }^{10)}$.また, $80 \mathrm{~Hz}$ 付近の
変調周波数を使用すると睡眠下の小児の反応が得られや すいとされるが11), 今回 $\mathrm{AM}^{2}$ 音を使用し $80 \mathrm{~Hz}$ 付近の変 調周波数を用いたわれわれの経験では睡眠下の乳幼児に おいても $0.5 \mathrm{kHz}$ の ASSR は検出しにくい傾向であった. $0.5 \mathrm{kHz}$ の ASSR に関してはわれわれと同様の報告もあ るが 12) 15), 他の周波数と同様の純音との相関を示した 良好な成績の報告もある ${ }^{6) 16)}$ ，それらの例では，われわ れの用いた変調周波数とは異なる刺激音を用いたか，検 查時間が長く設定してあるために検出が良かった可能性 もある。また，対象症例が小児であるため behavioral 

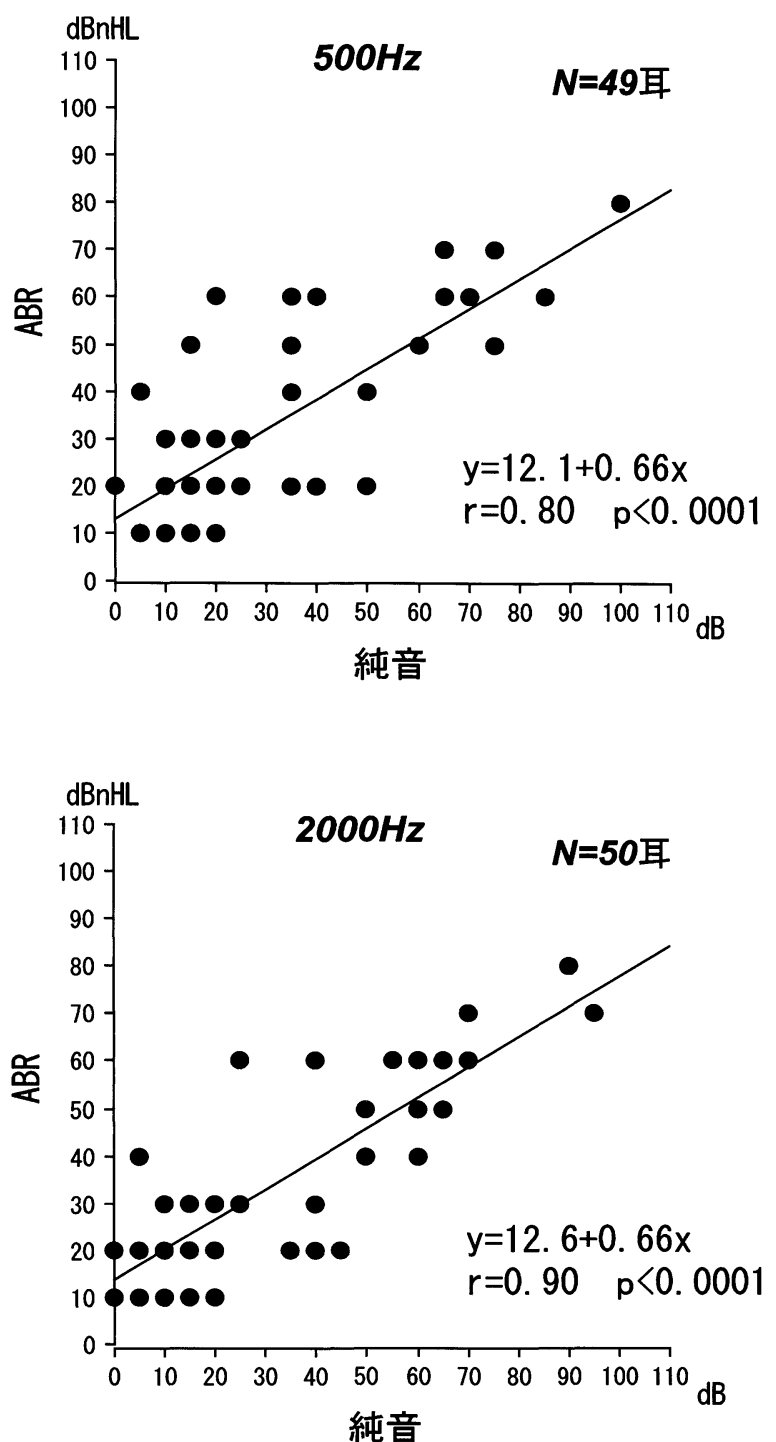
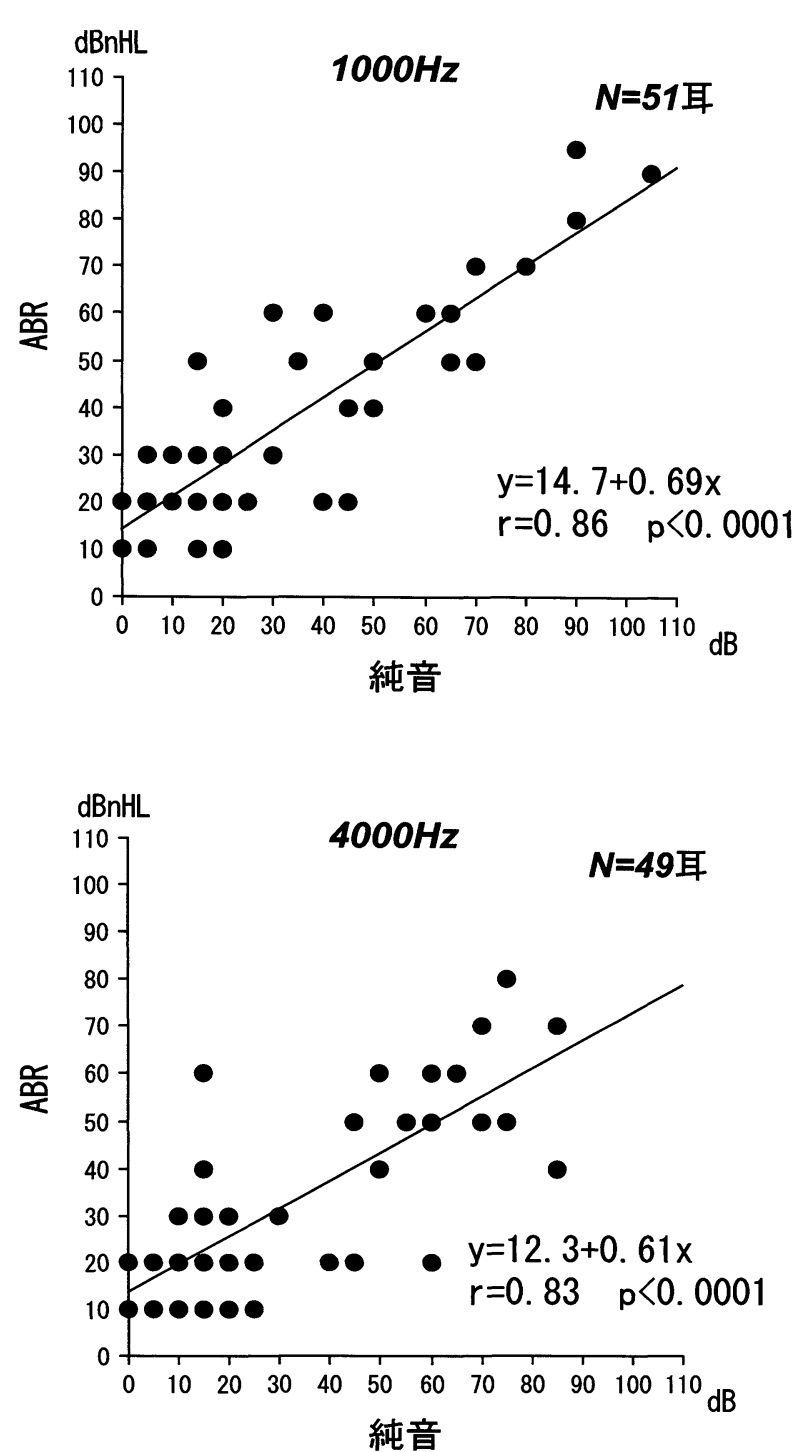

図 3 純音閾値と $A B R$ 閾値の相関

audiometry の閾值が悪かったために $0.5 \mathrm{kHz}$ の相関が良 かった可能性も考えられる。

今回の検討において， $0.5 \mathrm{kHz}$ においても純音と click 音刺激の $\mathrm{ABR}$ の閾值の間に有意な相関がみられたこと は，対象聴力の聴力像が水平型あるいは漸傾型がほとん どであったことに起因すると考える.しかし， $0.5 \mathrm{kHz}$ においてASSR と純音との閾值の相関がABR との相関を 上回らなかったことは，低周波数域の他覚的検查として 用いるためには周波数特異性を保ちながら検出率が最善 となる変調周波数, 測定条件の検討がさらに必要である と考えた。
補充現象のために難聴者の ASSR の閾值と純音閾值が 近似し，正常聴力者では両者の乘離が大きくなることは 指摘されているが2)10117)18), 今回の正常者および難聴者の 相関関係からもそのことが裹付けられた. 今後, 複数施 設のデータを用いて, MASTER ${ }^{\circledR}$ で得られた閾值に対し，

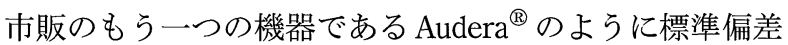
を示し適正な補正值を示すことができればより実用的な 検查となりらると考える.

MASTER ${ }^{\circledR}$ ではABRの測定と同等の 30 分〜 1 時間の短 時間で左右同時に複数周波数の閾值が得られ聴力像のプ ロフィルを描くことが可能である. 今回の検討では, 0.5 
〜 $4 \mathrm{kHz}$ のすべての周波数において純音と ASSR の閾值 が $30 \mathrm{~dB}$ 以内であった症例は 126 耳中 72 耳（57\%）と， 純音とほぼ一致する例は比較的多かった。

また, MASTER ${ }^{\circledR}$ の閾值の判定が FFT 解析を用いた自 動判定であることは，肉眼で判定できない反応を閾值と して判定することができ，客観的検査が可能である．今 後 behavioral audiometry の困難な生後 5 力月までの乳幼 児や発達遅滞のある症例の他覚的検査として大いに期待 されるが，純音閾值と一致しない症例もあるので周波数 特異性と検出率が最善となる变調周波数，測定条件の設 定がさらに必要であると考えた。

\section{まとめ}

1. 聴力正常成人の純音とASSRの閾値を検討したとこ ろ,ASSRの閾值は $0.5 \mathrm{kHz}$ において純音閾值より約 $30 \mathrm{~dB}$ 高く, $1 \sim 4 \mathrm{kHz}$ において約 $20 \mathrm{~dB}$ 純音閾值より高かった.

2. $80 \mathrm{~Hz}$ 付近の変調周波数を用いた睡眠下の乳幼児例 の記録においても，ABR の閾值が平均 $20 \mathrm{dBnHL}$ である のに対し，ASSR の各周波数の閾值は $35 \sim 55 \mathrm{dBnHL}$ と 高く, 特に $0.5 \mathrm{kHz}$ の反応が検出されにくく閾值が高い 傾向がみられた。

3. 6 ～ 81 歳を対象とした純音と ABR，ASSR の各閾 值の相関では，0.5〜4kHz の各周波数において純音に 対する ABR とASSR の相関は同等であった。

4. MASTER ${ }^{\circledR}$ のらなる臨床応用については, $0.5 \mathrm{kHz}$ の検出度を改善するため変調周波数, 測定条件をさらに 検討し S/N 比を改善する必要があると考えた。

5. MASTER ${ }^{\circledR}$ で得られた閾值に対して標準偏差を示 すことができれば，より実用的な検査となりうると考え た.

\section{参考文献}

1) Richards FW and Clark GM : Steady-state evoked potentials to amplitude modulated tones. Evoked Potentials II, (ed by Nodar RH and Barber C). pp 163 168, Butterworth, Boston, 1984.

2) Lins OG, Picton PE, Picton TW, et al. : Auditory steady-state responses to tones amplitude-modulated at $80-110 \mathrm{~Hz}$. J Acoust Soc Am $97: 3051 \sim 3063,1995$.

3) 大西信治郎：他覚的聴力検查，聴性脳幹反応. $211 \sim 221$ 頁，メジカルビュー社，東京，1985。

4）伊藤 吏，渡辺知緒，阿部靖弘，他：聴性定常反応を用い た他覚的聴力検查システム MASTER ${ }^{\circledR}$ の有用性について. Audiology Japan $48: 128 \sim 134,2005$.
5）増田正次, 井上泰宏, 佐藤美奈子, 他：純音聴力レベルと 聴性定常反応を利用した推定聴カレベルとの比較. Audiology Japan $47: 207 \sim 213,2004$.

6) Stueve MP and O'Rourke C : Estimation of hearing loss in children: comparison of auditory steady-state response, auditory brainstem response, and behavioral test methods. Am J Audiol $12: 125 \sim 136,2003$.

7) Picton TW, Dimitrijevic A, Perez-Abalo MC, et al. : Estimating audiometric thresholds using auditory steady-state responses. J Am Acad Audiol $16: 140 \sim$ 156, 2005.

8) Picton TW, John MS, Dimitrijevic A, et al. : Human auditory steady-state responses. Int J Audiol $42: 177 \sim 219,2003$.

9）神田幸彦，酒井秀嗣：当施設で行っている乳幼児精密聴力 検査としての MASTER の検討. Audiology Japan $48: 187$ 〜 195, 2005

10) John MS and Picton TW : Human auditory steady-state responses to amplitude-modulated tones: phases and latency measurements. Hear Res 141: $57 \sim$ 79, 2003.

11）青柳 優，鈴木 豊, 渡辺知緒, 他：変調周波数追随反応 の成立機序に関する検討. Audiology Japan $47: 214 \sim 221$, 2004.

12) John MS, Brown DK, Muir PJ, et al. : Recording auditory steady-state responses in young infants. Ear Hear 13:1 36, 2004.

13) Rickards F, Tan L, Cohen L, et al. : Auditory steady-state evoked potentials in newborns. Br J Audiol $28: 327 \sim 337$, 1994.

14) Rance G, Rickards F, Cohen L, et al. : The automated prediction of hearing thresholds in sleeping subjects using auditory steady-state potentials. Ear Hear 16 : $499 \sim 507,1995$.

15) Cone-Wesson B, Rickards F, Poulis C, et al. : The auditory steady-state responses: clinical observations and applications in infants and children. J Am Audiol $13: 270 \sim 282,2002$.

16) Schmulian D, Swanepoel D and Hugo R : Predicting pure-tone thresholds with dichotic multiple frequency auditory steady state responses. J Am Acad Audiol $16: 5 \sim$ 17, 2005.

17) Swanepoel D, Hugo R and Roode R: Auditory steady-state responses for children with severe to profound hearing loss. Arch Otolaryngol Head Neck Surg $130: 531 \sim 535,2004$.

18) Dimitrijevic A, John MS, Van Roon P, et al. : Estimating the audiogram using multiple auditory steady-state responses. J Am Acad Audiol $13: 205 \sim 224,2002$.

原稿受付：平成17年 8 月 24 日

原稿採択：平成17年10月12日

別刷請求先：武田真紀子

于683-8504 鳥取県米子市西町36-1

鳥取大学医学部耳鼻咽喉・頭頸部外科学分野 